\title{
SPOT-NUMBER IN MANIOLA JURTINA-VARIATION BETWEEN GENERATIONS AND SELECTION IN MARGINAL POPULATIONS
}

\author{
PAUL BRAKEFIELD \\ Department of Genetics, University of Liverpool, Liverpool L69 3BX*
}

Received 22.ix.78

\begin{abstract}
SUMMARY
A means of investigating selection in marginal populations by analysing the change in variation between generations within them is described. It is illustrated by the analysis of spot-number variation in Maniola jurtina. A greater constancy of female spot-average between generations is found within both the more marginal populations of central-eastern Scotland and the peripheral populations of the Isles of Scilly than within those more centrally located in southern England. This result is discussed in relation to the ways in which selection may act in marginal populations.
\end{abstract}

\section{INTRODUCTION}

MANY workers have pointed out that the genetic structures of populations of a species inhabiting the central and marginal parts of its distribution are likely to be characteristically different (e.g. Dobzhansky et al., 1963; Mayr, 1970). It is often considered that central populations tend to be adjusted to a wider range of ecological environments and thus to have achieved a more secure and stable adaptedness to their environment than marginal ones, which may well only be able to survive in a more limited adaptive zone or ecological niche. Carson (1959) has called the natural selection which predominates in central populations heteroselection, and considers that it favours polymorphism, restricted recombination and a general adaptedness to a multiplicity of conditions. In contrast marginal populations are dominated by homoselection which favours a relative homozygosity, random genetic drift, free recombination and adaptive specialisation.

Numerous comparative studies of genetic variation within groups of populations differing in their degree of marginal isolation have been undertaken. Sometimes the analysis of different types of genetic variation in a species has led to divergent results. Carson (1965), for example, has shown that in various species of Drosophila, including $D$. robusta, the central populations are highly polymorphic for chromosome inversions whilst the marginal populations have either greatly reduced or no inversion polymorphisms. Prakash (1973), in contrast, found in a survey of 20 allozymes in $D$. robusta that the proportion of polymorphic loci and the average heterozygosity per individual was slightly higher in the marginal populations than the central populations.

This paper describes a different means of investigating selection in marginal populations by comparing the change in variation from one generation to another within the populations of regions which differ in their

* Present address: Rembrandtlaan 138, Middelharnis, Holland. 
marginality. The variation analysed is that in the number of submarginal spots on the hindwings of the univoltine butterfly, Maniola jurtina (for a review, see Ford, 1975). The frequencies of the spots are different in the sexes. Spot-number behaves as a polygenic character. McWhirter (1969) has estimated that at $15^{\circ} \mathrm{C}$ the heritability is rather high in the females $(0.63 \pm 0 \cdot 14)$ and lower in the males $(0 \cdot 14)$. It increases with a rising temperature (reported in Ford, 1975).

The analysis for both sexes uses the spot-average values for the samples of each generation from each population. A separate one-way analysis of variance is done for each region, extracting the error terms $\sigma_{c}^{2}$ or $\sigma_{m}^{2}$. These represent estimates of the variance between generations common to all populations within a central and a marginal region respectively. The variance ratios of the form $\sigma_{c}^{2} / \sigma_{m}^{2}$ can then be calculated.

\section{STUdy AREAS}

From 1973 to 1977, populations were sampled in a region extending from the east coast of Scotland inland to the Central Lowlands, eastern Grampian Mountains and the Sidlaw Hills. $M$. jurtina approaches the northern limit of its distribution in central-eastern Scotland. The existence of a distinctive spot-frequency in part of the region, the Grampian Mountains, may also be an indication of its marginal status. Dowdeswell and McWhirter (1967) found that in areas towards the edge of the species' distribution, distinctive spot-frequencies occur. Several of the populations studied were also strongly marginal in the sense of occupying the highest-sometimes exceptionally so-altitudinal zone that the species reaches in Scotland. A complete description of the populations together with the full data will be given elsewhere (Brakefield, in preparation).

Creed et al. (1959 and 1962) published data on spot-number variation from populations of $M$. jurtina in the region of southern England extending eastwards from east Dorset to the East Anglian coast. This region lies within the considerably larger "General European" stabilisation area which extends throughout the central part of the species' distribution. Almost all populations within this stabilisation area are characterised by a similar spot-frequency (Dowdeswell and McWhirter, 1967). No populations are included in the southern England group which could be considered as being situated within the region of transition between different stabilisations of spot-frequency that occurs in south-west England (see Ford, 1975). As in Scotland, the southern English populations were sampled during a 5 -year period (1956-60), over which the whole flight period was covered. Only those populations in both regions for which at least two samples, each of 15 or more specimens of both sexes, were obtained are included in the analysis. The total number and distribution of the samples in time was similar for the two regions and the number of populations $(n=15)$ sampled in each was fortuitously equal.

A third area where populations of $M$. jurtina have been sampled over many years is the Isles of Scilly archipelago which is situated off the south-west coast of England. This region lies outside the "General European" stabilisation area. Populations are found within it which show a number of different forms of spot-frequency. Dowdeswell and McWhirter (1967) consider it to be a peripheral area within the species' distribution in which 
populations are adjusted to specialised environments. The 5-year period, 1953-57, of intensive sampling was arbitrarily selected for this study as it immediately follows 1952 when no field-work was carried out. During this period, a total of eight populations from the three large islands together with three of the small islands were each sampled in at least 3 years (Dowdeswell et al., 1957, 1960). Only the data for the female are sufficiently extensive to include in the present analysis.

\section{Results}

The results of the analysis of variance (table 1) suggest that a significantly lower variability in female spot-average, from one generation to another, occurs within the populations both of Scotland and of the Isles of Scilly than within those of southern England. The absence of any corresponding difference for Scotland and southern England in the male may reflect the relative stability of spot-variation that is generally found within this sex (McWhirter, 1957; Handford, 1973).

\section{TABLE 1}

(i) Analysis of variance of spot-averages for yearly samples from populations of $\mathrm{M}$. jurtina

\begin{tabular}{|c|c|c|c|}
\hline ur & $\begin{array}{l}\text { Sum of } \\
\text { squares }\end{array}$ & $\begin{array}{l}\text { Degrees of } \\
\text { freedom }\end{array}$ & $\begin{array}{l}\text { Mean } \\
\text { square }\end{array}$ \\
\hline
\end{tabular}

(a) Central-eastern Scotland-female samples

Population
Year (error term)
Total

(b) Isles of Scilly-female samples

Population

$\begin{array}{llll}3 \cdot 2420 & 14 & 0.2316 & 10 \cdot 39 * * * \\ 0.9608 & 43 & 0.0223 & \end{array}$

$4 \cdot 2028 \quad 57$

Year (error term)

$3 \cdot 8251$

$0.3534 \quad 23$

$4 \cdot 1785 \quad 30$

(c) Southern England-female samples

Population

$\begin{array}{llll}1.2696 & 14 & 0.0907 & 2 \cdot 08\end{array}$

Year (error term)

Total

$1 \cdot 6184$

37

$0 \cdot 0437$

$35 \cdot 48 * * *$

$0 \cdot 5464$

0.0154

$2 \cdot 8880$

51

(d) Central-eastern Scotland-male samples

Population

$1 \cdot 4400$

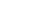

Year (error term)

Total

0.9367

14

36

$0 \cdot 1029$

0.0260

$3 \cdot 96 * * *$

(e) Southern England-male samples

Population

$2 \cdot 3767$

50

Year (error term)

0.4095

0.9097

14

37

0.0292

0.0246

$1 \cdot 19$ Total

$1 \cdot 3191$

51

(ii) Variance ratios of year (error term) mean squares (female comparisons are given to the top right and male to the bottom left of the table)

$\begin{array}{cccc}\text { Area } & \begin{array}{c}\text { Central-eastern } \\ \text { Scotland }\end{array} & \begin{array}{c}\text { Southern } \\ \text { England }\end{array} & \begin{array}{c}\text { Isles of } \\ \text { Scilly }\end{array} \\ \begin{array}{c}\text { Central-eastern } \\ \text { Scotland }\end{array} & - & 1.96^{*} & 1.45 \\ \begin{array}{c}\text { Southern } \\ \text { England }\end{array} & 1.06 & - & 2.84^{* *}\end{array}$

Degrees of freedom may be abstracted from part (i) above.

$* \mathrm{P}<0.05 ; * * \mathrm{P} \approx 0.01 ; * * * \mathrm{P}<0.001$. 
Most of the Scottish populations were apparently characterised by a lower population size and density (Brakefield, in preparation) and a shorter flight period, and they were probably more isolated from their neighbouring populations than were those more centrally located in southern England. $M$. jurtina can probably be considered to be a species in which a marginal population is likely to inhabit a more restricted adaptive zone or ecological niche.

As a consequence of the proposed predominance of homoselection in marginal populations and their adaptive specialisation, it may be predicted that the natural selection acting on individuals within them will tend to do so between narrower limits and be more similar from one individual to another than in central populations. This may in turn produce a higher degree of genetic homozygosity and therefore of genetic inflexibility. These factors may tend to limit the range and form of genetic variation which one marginal population can assume relative to a central population (although marginal populations may be more heterogeneous as a whole). A marked environmental shift (and thus one in selection) might therefore be more likely to result in a relatively abrupt change in population size, or even extinction, rather than in genetic variation within the population. The last might occur more readily in the, on average, environmentally more diverse and larger central populations.

If these predictions are used to formulate the hypothesis that the variability of female spot-average between generations in the more marginal Scottish populations is less than in southern England, then the field results support it at the $2 \cdot 5$ per cent significance level. The corresponding twotailed test, with no a priori prediction to expect one or the other variance to be greater, shows that the variances are not identical at the 5 per cent significance level. For one variable at least, the results of this study therefore tend to substantiate the prediction of less variability between generations in more marginal populations, this resulting from homoselection and adaptive specialisation.

Many populations in the Isles of Scilly, unlike those in Scotland, are large and at a high density (Dowdeswell et al., 1949). They also show an extended flight period in comparison with the mainland (Ford, 1975). Thus they appear to occupy a highly suitable habitat. Rather than being marginal, in the sense of inhabiting an environment close to the biological limit for the species, these populations are probably more aptly considered as peripheral, their spread being prevented solely by a geographical barrier (the sea). Although these island populations probably inhabit relatively specialised environments (Dowdeswell and McWhirter, 1967; Ford, 1975), factors other than those acting in the marginal populations of Scotland may also be involved in producing the lower variability between generations that is found within them than in southern English populations.

A fairly high proportion (23-32 per cent) of the spot-average values for individual generations are not available for the populations of each region. Furthermore, the three sampling periods were not concurrent and the size of each region and the distribution of populations within them was different. These considerations suggest that it may be inadvisable to draw any firm conclusion on the basis of these results or to proceed further with the analysis of variance.

An attempt to circumvent the problem of missing spot-average values 
can be made by analysing the absolute values of the differences between the female spot-averages of consecutive samples (generations), in relation to region. The means, with standard errors, of the three groups of " difference values" are $0.160 \pm 0.023$ for Scotland $(n=37), 0.153 \pm 0.025$ for the Isles of Scilly $(n=19)$ and $0 \cdot 235 \pm 0.037$ for southern England $(n=35)$. The means for the Isles of Scilly and southern England are not significantly different $\left(t_{(52)}=1 \cdot 52\right)$. Those for Scotland and southern England are significantly different when a one-tailed test is used with the $a$ priori expectation that the mean for Scotland (and hence variability from one generation to the next) is less than that for southern England $\left(t_{(70)}=1 \cdot 74\right.$, $\mathrm{P}<0.05)$. However, the variances of the two groups of "difference values" are significantly different $\left(F_{(34,36)}=2 \cdot 42, \mathrm{P}<0.01\right)$. A MannWhitney test was therefore performed; the change between consecutive generations did not then remain significantly less in Scotland than in southern England $\left(Z_{(36,34)}=1 \cdot 545,0 \cdot 1>P>0.05\right)$. There is thus some indication that the change in female spot-averages between consecutive generations (without taking the variability between populations into account) is, on average, less in marginal populations than in more central populations.

Populations in southern England are spatially more continuous than those in the Isles of Scilly. The populations from the different islands within the Isles of Scilly are isolated from one another (Dowdeswell et al., 1949). Adult movements of up to several hundred metres have been detected from, or between, centres of relatively high density at a number of mainland sites (Brakefield, in preparation). Interpopulation migration is therefore likely to occur to a greater extent in southern England, possibly leading to a more frequent introduction of novel genetic combinations into populations in this region. The higher variability between generations within the southern English populations might then, in part, represent a consequence of a greater gene flow between them. However, table 1(i) shows that there is no significant variability in either sex between the southern English populations and therefore any interpopulation migration is unlikely to introduce novel genetic combinations into them. Nevertheless, in view of the probable absence of gene flow between island populations in the Isles of Scilly, even a low rate of introduction of such genotypes into southern English populations might produce a relative difference in variability between generations. A reduced gene flow could also contribute to a lower intergeneration variance in marginal populations where these are more isolated from one another than are central populations. This may therefore be an additional factor when the populations of Scotland and southern England are considered, although the lack of heterogeneity amongst the southern English populations suggests that it is unlikely to be the principal one.

There is a highly significant variability between female populations in the Isles of Scilly (table l(i)) which may, in part, reflect their isolated nature. It is significantly greater than that of the southern English populations (table 2). A similarly high heterogeneity is shown in each sex by the Scottish populations. In the male this is greater than that of the southern English populations. As indicated above this might be predicted in more marginal populations when each of these tends to occupy a particular specialised environment. However, this difference does not remain significant when 
the Grampian Mountains populations with their distinctively high spotaverages are excluded from the analysis (table 2). In the female this procedure reverses the relative degree of variability within the two corresponding groups of populations. It also produces a significant difference in variability between the female populations in the Isles of Scilly and those in Scotland.

TABLE 2

(i) The variances of the mean spot averages for the populations of each region

Source of variation $\overbrace{\text { Female }}^{\text {Variance-s }-s^{2}}$ Male $\quad \begin{aligned} & \text { Number of } \\ & \text { populations }\end{aligned}$

Central-eastern Scotland:

$\begin{array}{llll}\text { All populations } & 0.0562 & 0.0262 & 15\end{array}$

$\begin{array}{lll}\text { Not incl. Grampian Mts. } & 0.0102 & 0.0148\end{array}$

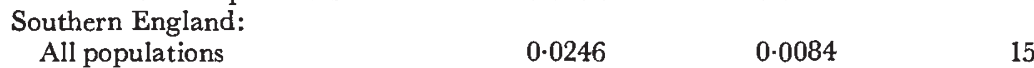

Isles of Scilly:

(ii) Variance ratios of the population mean spot averages (female comparisons are given to the top right and male to the bottom left of the table)

\begin{tabular}{|c|c|c|c|c|}
\hline & \multicolumn{2}{|c|}{ Central-eastern Scotland } & \multirow[b]{2}{*}{$\begin{array}{l}\text { Southern } \\
\text { England }\end{array}$} & \multirow[b]{2}{*}{$\begin{array}{c}\text { Isles of } \\
\text { Scilly }\end{array}$} \\
\hline Area & $\begin{array}{c}\text { All } \\
\text { populations }\end{array}$ & $\begin{array}{c}\text { Not incl. } \\
\text { Grampian Mts. }\end{array}$ & & \\
\hline ntral-eastern Scotland: & & & 2 & 0.57 \\
\hline Not incl. Grampian Mts. & - & - & $2 \cdot 41$ & $14 \cdot 14 * * *$ \\
\hline Southern England & $3 \cdot 10^{*}$ & $1 \cdot 75$ & - & $5 \cdot 87 * *$ \\
\hline
\end{tabular}

Central-eastern Scotland:

Degrees of freedom may be found by reference to the " number of populations" as given in part (i) above.

$* \mathrm{P}<0.05 ; * * \mathrm{P}<0.01 ; * * * \mathrm{P}<0.001$.

\section{Discunsion}

The results of the comparison of the spot-variation between populations of $M$. jurtina in one marginal, one peripheral and one central region are strongly affected by the exclusion of three neighbouring populations from the former. These populations are characterised by a distinctive form of spot-frequency. Comparative studies of this type are open to various sources of error including the selection of the populations to be studied.

In the present study an alternative means of investigating selection in groups of populations by analysing the change in variation between generations is developed. The results suggest that selection which leads to less change in phenotypic and genetic variation and a relative inflexibility may be acting in the marginal populations of $M$. jurtina in comparison with those more centrally located. This is consistent with the suggestion that homoselection favouring a relative homozygosity predominates in marginal populations.

Alternatively it can be argued that marginal populations (providing they have some genetic heterogeneity) through their, on average, reduced environmental diversity and smaller size may be less well buffered against 
environmental fluctuation and so show more, rather than less, change in genetic variation between generations. Again, the likelihood of an environmental fluctuation acting on a marginal and a central population may not necessarily be equal. Such considerations may, in part, account for the divergent results which have sometimes been obtained. Selection may act in more than one way in marginal populations depending on the particular type of variation, population(s) or species that is investigated. As indicated above, other factors such as the extent of gene flow between populations may also contribute to differences between marginal and central populations.

Populations of $M$. jurtina generally include individuals of each of the spot phenotypes, although these may occur at widely differing frequencies in different populations. More or less abrupt transitions between different forms of spot-frequency (which have been termed "quantum" changes) have sometimes been detected, particularly in female populations. The data for the southern English populations which are analysed in the present study includes some examples of "quantum" changes (Creed et al., 1962) as do those for the Isles of Scilly populations (Dowdeswell et al., 1960). None have as yet been detected in Scotland. Changes of this type may occur more rarely in marginal than in central populations and they may represent an extension of the less pronounced variability that occurs between generations.

I suggest that the approach of studying the change in variation between generations is a valuable one where long-term field sampling of species with discrete generations is possible. Although open to similar sources of error to that of studying variation between populations it can provide an important additional means of investigating the action and effects of selection in marginal populations.

Acknowledgements.-This paper benefited considerably from the critical reading and comments of Dr J. A. Bishop, Professor A. J. Cain, Dr L. M. Cook, Dr E. R. Creed, Professor E. B. Ford, F.R.S. and Dr M. R. Macnair, together with those of an unknown referee. The field-work in Scotland was assisted by Dr D. R. Robertson and Dr G. Thomson. It was supported by Professor E. B. Ford, the Science Research Council and Pembroke College, Oxford.

\section{REFERENCES}

GARSON, H. L. 1959. Genetic conditions which promote or retard the formation of species. Cold Spring Harbor Symp. Quant. Biol., 24, 87-103.

GARSON, H. L. 1965. Chromosomal morphism in geographically widespread species of Drosophila. The Genetics of Colonizing Species. Academic Press Inc., New York.

GREED, E. R., DOWDESWELL, W. H., FORD, E. B., AND MCWHIRTER, K. G. 1959. Evolutionary studies on Maniola jurtina: the English mainland, 1956-57. Heredity, 13, 363-391.

CREED, E. R., DOWDESTELL, W. H., FORD, E. B., AND MGWHIRTER, K. G. 1962. Evolutionary studies on Maniola jurtina: the English mainland, 1958-60. Heredity, 17, 237-265.

DOBZHANSKY, TH., HUNTER, A. S., PAVLOVSKY, O., SPASSKY, B., AND BRUCE WALIACE. 1963. Genetics of natural populations. XXXI. Genetics of an isolated marginal population of Drosophila pseudoobscura. Genetics, 48, 91-103.

DOWDESWELL, W. H., FISHER, R. A., AND FORD, E. B. 1949. The quantitative study of populations in the Lepidoptera. 2. Maniola jurtina L. Heredity, 3, 67-84.

DOWDESWELI, W. H., FORD., E. B., AND MCWHIRTER, K. G. 1957. Further studies on isolation in the butterfly Maniola jurtina L. Heredity, 11, 51-65.

DOWDESWELL, W. H., FORD, E. B., AND MGWHIRTER, K. G. 1960. Further studies on the evolution of Maniola jurtina in the Isles of Scilly. Heredity, 14, 333-364.

DOWDESWELl, W. H., AND MCWHIRTER, K. G. 1967. Stability of spot-distribution in Maniola jurtina throughout its range. Heredity, 22, 187-210. 
FORD, Е. в. 1975. Ecological Genetics. Chapman and Hall, London.

HANDFORD, P. T. 1973. Patterns of variation in a number of genetic systenis in Maniola jurtina: the boundary region. Proc. Roy. Soc. Lond. B, 183, 265-284.

MCWHIRTER, K. G. 1957. A further analysis of variability in Maniola jurtina L. Heredity, 11, 359-371.

MCWHIRTER, K. G. 1969. Heritability of spot-number in Scillonian strains of the Meadow Brown Butterfly (Maniola jurtina). Heredity, 24, 314-318.

MAYR, E. 1970. Populations, Species and Evolution. The Belknap press of Harvard University Press, Cambridge, Mass.

PRAKASH, s. 1973. Patterns of gene variation in central and marginal populations of Drosophila robusta. Genetics, 75, 347-369. 